\title{
The Development of Smart Cities in India: A Smart Notion of Promoting Travel and Tourism
}

\section{Dr. Rekha Maitra}

Assistant Professor-Hotel Management, Manav Rachna International University, Faridabad,Haryana

\begin{abstract}
Travel and Tourism is regarded to be a dynamic, flexible and ever growing industry. Travel and tourism industry plays an imperative role in the economic development of a country.It develops cultural understanding and harmony amongst the different religions of a soveirgn country like India,being a land of diversity has its own culture and history in every metropolis. Harmony of different cultures makes it a distinguished and a spectacular country. The rich customs and legacy of India attract a large number of travelers to India.
\end{abstract}

"According to the report on 'India's Urban Awakening' by McKinsey Global Institute, in the succeeding 20 years, India can have 68 cities with a population over one million - up from 42 today". In comparison to European and American cities, Indian cities are far more crowded and complex. Consequently, India needs a far efficient and sustainable solution to tackle the situation. Therefore, "With the objective of promoting India on a world map PM. Modi had announced his vision to set up 100 smart cities across the country.. The 100 smart city mission intends to encourage acceptance of smart solutions for efficient use of available assets, resources and infrastructure". (Das, May 2015)

City's conversion into a smart city can offer numerous prospects to the citizens as well as the visitors. (Worstall, 2016) mentions with the rapid development of the Indian economy at 'the GDP of 7\%' $i$ the requirement of urban culture facilities has raised a demand of sustaining the growing population.

Keywords: smart city, technology, sustainability, development, Indian economy.

\section{BACKGROUND OF THE RESEARCH: ISSUES RELATED TO TOURISM DEVELOPMENT}

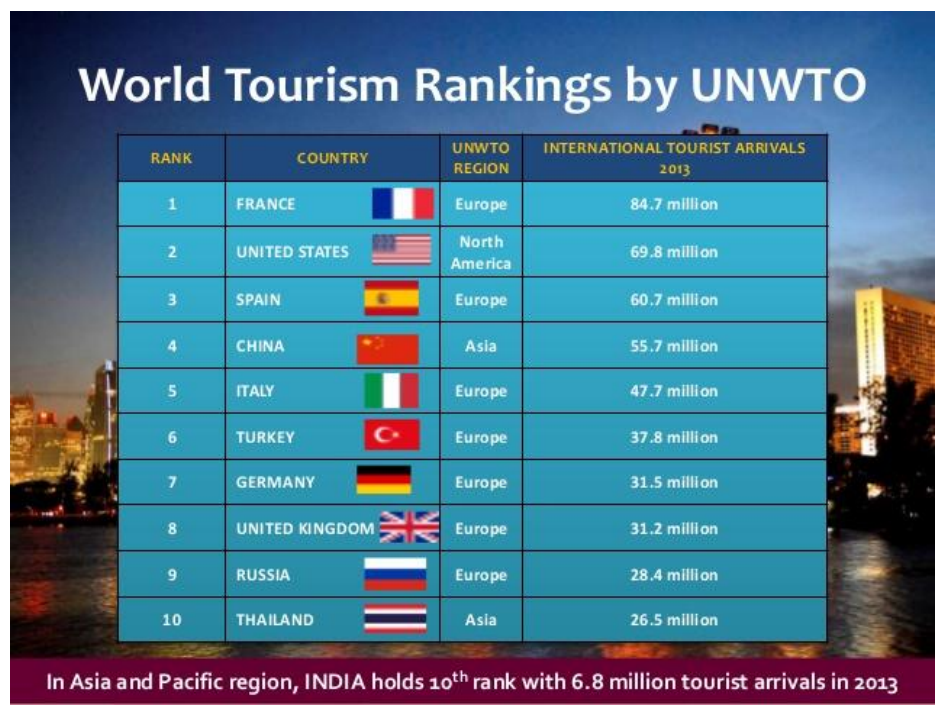

Figure1. World tourism ranking by UNWTO (Reference: UNWTO) ${ }^{i i}$

The above figure derived from UNWTO explains the non-existence of India amongst the world top destinations. The essence of Incredible India has failed to attract many potential buyers/ tourists due to various reasons.

(Murty) "Challenges like Indian political formation, land estimation challenges, competency gaps, funding deficit halts the development of new cities and holds India back from a new era of economic growth". 


\section{Dr. Rekha Maitra}

This conceptual paper will address these obstacles and how India as a nation can get rid of these obstructions. The paper will also address the current dilemma of owning high-quality infrastructure i.e "solid waste administration, flood management, storm water and sewer system etc. which have further resulted in urban decay, traffic congestion and significantly deteriorated quality of animation". (mygov.in, 2015). A fresh move is being adopted by the Government of India to transform the cities into smart cities to make them sustainable in a long run.

In 2015, Bloomberg Philanthropies partnered with the Ministry of Urban Development to support the Mission through the design and delivery of the India Smart Cities Challenge. Bloomberg the official partner of smart city mentions on its website (www.bloomberg.org) 'Urbanization in India is occurring at a breakneck pace. Its cities are expected to grow from 340 million people in 2008 to 590 million by 2030. The speed of growth in cities poses huge challenges, but also offers big opportunities. ${ }^{\text {iii }}$.

\section{OBJECTIVES}

The primary objective of this paper is to track the growth through the acceptance of smart culture. This paper will determine how the smart city can facilitate India to be promoted as a fully equipped smart destination for tourist.

The paper aims to decide the strategies adopted by other nations towards the smarter tourism. By adopting the strategies of other countries the tourist inflow is likely to increase, which may boost the Indian economy. This conjectural paper is based on the secondary data, which was compiled from the websites, newspapers, government portals, annual reports, articles and websites of Ministry.

\section{InTRoduCTION OF SMART CITY}

A smart city is one that has digital technology embedded across all city functions. (Kumar, July 1, 2015).A smart city lays the foundation of smart living, smart economy, smart governance, smart mobility and smart environment to its citizens. In other words, Smart city extends the facility of better livability, workability and sustainability.

"Smart cities are essentially urban clusters with smooth transportation, e-governance, and better social infrastructure, including health care and education.Smart is not just about technology-enabled, but also about power, water, transportation and solid waste management". (Kandpal, 2016)

The smart city is required to maintain transportation, IT connectivity, water and waste management. New smart cities with multiple provisions can overcome the urban decay and a more balanced distribution could be attained. With improved facilities, the tourism can boost up and the tourist can experience the unknown places. The investment in tourism sector by the private agencies and government authorities can help to generate sensible revenue for the government.

Smart cities not only serve the citizens who dwell in the city, but also accommodate those who visit. In this regard (Musa, 2016) pointed out that "A smart city is an urban development vision to integrate multiple information and communication technology (ICT) and Internet of Things (IoT) solutions in a secure fashion to manage a city's assets - the city's assets include, but are not limited to, local department information systems, schools, libraries, transportation systems, hospitals, power plants, water supply networks, waste management, law enforce ment, and other community services". iv

Smart city has the ability to improve quality of life by the constant usage of technology .The online services can increase the efficiency of services by offering the real time data.With the help of information technology the officials and the community can manage and access each other easily.

According to ((W3C/CTIC), 2009) "Current Web technology allows governments to share with the public a variety of information in unlimited quantities on demand. Technology is also available to allow citizens to bring issues of concern to the attention of local, regional and national governments".

"The processing and analyzation become easier for the citizens with the help of devices, thus enabling a better quality of life. Information and knowledge turn out to be an important instrument for effective performance". (Dutt, 2015)

The concept of Smart city denotes a smart culture with a neat and tidy environment wherein the residents and the tourist are provided with best infrastructure to fit their daily necessities and live a good life in a sustainable environment. These cities are required to maintain sustainability with regard 
to sanitation management and better connectivity. An initiative by Government of India of converting the cities into Smart cities to promote tourism and employment opportunities.

Bloomberg has signified the importance of smart city on its website (www.bloomberg.org) "Smart cities focus on their most pressing needs and on the greatest opportunities to improve lives. They tap a range of approaches-digital and information technologies, urban planning best practices, publicprivate partnerships and policy change to make a difference.for always putting the people first".

Pradeep Kumar an author of http://www.smartcitiesprojects.com/ suggests "A city can be defined as 'smart' when investments in human and social capital and traditional (transport) and modern (ICT) communication infrastructure, fuel sustainable economic development and a high quality of life, with a wise management of natural resources, through participatory action and engagement".

"Smart cities can be broadly classified into three types - new cities, existing cities made smart and purpose driven cities To attract tourists and businesses these cities offer quality services by integrating information and communications technology in all facets". (Wakefield, 2015)

"Transforming existing cities into smart cities is a footstep by step process by integrating new processes into older systems. Purpose driven cities could be industry-centric, built around science towns. Overall, smart cities promise to provide quality of lifespan" (Dutt, 2015)

\subsection{Example of First Fully Planned Smart City in India- LAVASA}

Great dreams are realized only by planning. Lavasa, a planned hill station in Maharashtra, is one such case.. It is developed primarily by Hindustan Construction Company (HCC) India and is set amidst 7 hills and $60 \mathrm{~km}$ of lakefront and spread over 25,000 acres. It is anticipated to provide abundant opportunities as a global leader in Hospitality, Health and Wellness, Education sector for setting up tourism institutions. (Rvo, 2015)

\subsection{Example of New Delhi- Capital of India}

As per the latest news, the urban development minister Naidu directed the NDMC officials that the Rs 10.9 billion "Smart City" project should be implemented by June 2018 and the efforts should be visible by next June. According to Mr.Naidu "NDMC can become a lighthouse for other cities to develop as a smart city" (ibpsguide.in, 2016)

According to the reports on smart city, "a digital screen should be set up at all major NDMC locations to display useful information such as weather, traffic flow, suggested traffic diversions and pollutions. This kind of information should be provided on a continuous basis through the FM and community radio stations". (ibpsguide.in, 2016) besides this the whole NDMC area should be connected with the Wi-Fi installation.

(Pradeep Kumar 2016) a columnist of smart city news pointed "Projects costing Rs 650 crore have been taken up. NDMC chairman Naresh Kumar informed that the Centre's most ambitious 'Smart City Project' is based on four major pillars such as fresh water management, smart energy grid, smart training and smart health care. The smart healthcare project has been launched with few more are in the pipeline, about 25 of such projects would be finished by next June". v

\subsection{Tourism Prospects in the Current Era}

Domestic and Inbound Tourism - Statistics reveal that domestic tourism spending in India has valued expenditure of INR2.9 trillion in 2013, while inbound tourism expenditure totaled INR344.2 billion. (Timetric, 2014)

"FTAs during the Month of August, 2016 were 6.70 lakh as compared to FTAs of 5.99 lakh during the month of August, 2015 and 5.76 lakh in August, 2014. There has been a maturation of $11.8 \%$ in August, 2016 over August, 2015”. (Kakodkar, 2016)

The primary factors for tourism growth were government initiatives and continuous attempts to further the country's travel and tourism sector on an international level. Infrastructure development, road shows and tourist attraction development within the country also contributed towards the country's tourism growth. (Timetric, 2014)

The positivity of smart cities is likely to attract the investors, especially in the travel industry. With safer environment and upgraded facilities, people from foreign nations are likely to increase for big 


\section{Dr. Rekha Maitra}

business and leisure time. The increase in Foreign tourist arrival (FTA's) will increase the Foreign exchange earnings (FEE), which will further promote the economic development of the nation.

As per the government's perspective, operating on both International markets and domestic tourism infrastructure is a move in strengthening tourism sector. "The Finance Minister of India has put forward that they can lower taxes, make the railways and other infrastructure better as well as efficient enforcement of law and order for improving the fortunes of tourism industry". (Yadav, 2015)

\section{SMART TOURISM: INITIATIVES TAKEN BY OTHER COUNTRIES}

A smart city endows the tourist with the options of booking an oudoor as well as indoor tours on their smart applications through the smart phone.It helps the user to take a virtual tour of the city, use real time data i.e google maps to experience the mobility and traffic on the road.Due to the vast availability of Wi-Fi hotspot these apps turns out to be a boon in the form of a trusted guide for receiving the information and venturing the e-world of shopping arcades, food joints, availability of various services etc.

Barcelona comes under top cities in the world ranks. Because of better technology, the World Expo was held here so that people can insure the development of here. Well-known companies from all around the globe were invited. . (Journaldunet)

Master cards 2014 Global Cities Index ${ }^{\mathrm{vi}}$ carried the survey of world's top 132 destination cities and discovered that foreign exchange earnings increased three times faster in comparison to past five years than the overall world economic system developed.

The initiatives taken by the top destination smart cities are as follows:

- (Journaldunet) explains the easy accessibility of Smartphone apps, which has been enabled at London to aid the travelers to find their path round the city, book clubs and bicycles, and take share in cultural activities and events. The London tourism website offers the information of the most useful apps, free WiFi hotspots without additional roaming charges".

- (yoursingapore) the official website of Singapore showcases how a traveler in Singapore can buy a special SIM card at $\$ 15$, which provides the access to the traveller's app content without international roaming data charge or a WiFi hotspot. The card offers the discounts and exclusive benefits at certain Merchandisers ${ }^{\text {vii }}$.

- (tmb, https://www.tmb.cat/) website represents the overhauling of the bus system in Barcelona for crafting the new bus routes which save time as well as energy. Interactive bus shelters also provide travelers with information on when their bus will arrive, and give them USB ports to charge their mobile devices.

- (tmb, https://www.tmb.cat/) website showcases the availability of 6,000 bicycles to travelers in 400 locations throughout the Barcelona. Travelers can check on availability of bikes through a smartphone app. For those who need to travel by car, another app shows the real-time availability of parking spaces ${ }^{\text {viii }}$

- (tmb, https://www.tmb.cat/ca/) website explains the benefits of apps for helping local tourists in top destinations. The apps range from offering information on parking spots or connecting visitors with tour guides in a city like Paris. These data driven to apps provide the information about how tourists can access the internet on their own mobile devices, for example by providing free wifi in a city like Bordeaux ( France) ${ }^{\text {ix }}$

(Sharma, 2016) on smartcityprojects.com signifies the extended funding of Germany to India for the development of the high-speed railway, smart cities, and renewable energy. A Senior Official Uwe Beckmeyer said that Germany wants to support India. According to,Uwe Beckmeyer "Germany's economy and exports are on a good path. We need to strengthen our business abroad"”

\section{DISCUSSION}

Smart city is likely to offer world-class facilities with 24-hour power supply and drinking water, mass rapid urban transportation, with bicycle and walking tracks, complete waste and water recycling, systems for smart grids - digitally managed systems to control energy consumption - and smart metering. As per a report on Smart cities in India in the year 2016 (NL, 2016) " The industrial hubs 
and eco-friendly cities along the Delhi Mumbai Industrial Corridor (DMIC) are expected to double employment opportunities, triple industrial production and increase exports by four folds over the next decade touring vehicles etc.".

A Smart city is needed to satisfy the following criteria:

- Adequate and safe drinking water supplies.

- Guaranteed 24-hour power supply.

- Sanitation and solid waste management.

- Intuitive and accessible urban transport.

- Affordable housing on price.

- Maximum use of information technology.

- Clean and pollution free environment.

- Enough civil protection.

- Reuse of use water.

- Provision for the use of alternative energy ${ }^{\mathrm{xi}}$

A smart city has numerous ways to promote it , online, offline and directly on site by every attraction or tourist facility. (Ebi, 2014) Smart cities are likely to offer many choices to the travelers through the use of information technology.Tourists is enabled to customize their bookings as per their requirements.It also enables them to get a glimpse of the product through the virtual product.

This smart system of smart apps has deeply penetrated into our life as a part and parcel of our life.Be it the booking of a hotel, a cab, dining space in a restaurant, train, or any other facility etc..Today's tech-savvy, smart customers want to make a booking of a ancillary services for himself or herself through the web, from the comfort of the house or office.

As per the news in Financial express (Financial Express, Smart City full list, 2015) "Union Minister of Urban Development, Venkaiah Naidu declared nominations of 100 cities in an NDA government's flagship program. The Centre has earmarked Rs 48,000 crore for development of 100 smart cities. Each smart city would get a Central assistance of Rs 100 crore per year for five years".

The cities were selected through intra-city competition evaluated on parameters such as service levels, fiscal and institutional capacity, past track record and reforms". (Financial Express, Smart City full list, 2015)

\section{SMART CITY: INITIATIVES BY GOVERNMENT OF INDIA}

Ministry of Urban Development, Government of India has taken the initiative of converting the cities into a smart city. The website of smart cities.gov.in having a weblink of smart city literature, i.e. smart city, its features,strategy, challenges and cities profile etc.. The website has the information about the selection process, coverage and duration cover 100 cities with a duration of 5 years (FY 2015-16 to FY 2019-20).City wise projects under Smart city mission have been enlisted. 20 cities have been put on the priority for round one .13 cities are being put into fast track and for round two 16 cities have been selected. (Mygov.in, 2015)

List of Projects of Rs. 100 Crore and above as per SCPs of 60 Smart Cities are listed on the http://smartcities.gov.in/writereaddata/List_of_Projects_60_Cities.pdf under the heading of the name of a city, ABD,PAN,Nature/Sector, Project name and Amount in crores.

India is the fastest developing economy in the world today - an impressive position it has retained since it swept China in the year $2015^{\mathrm{xii}}$ - with the International Monetary Fund (IMF) predicting that India is likely to retain this status till 2020. With the Gross Domestic Product (GDP) of the country growing at more than 7\% since 2014, the IMF has kept projections for India's growth in 2016-2017 at $7.5 \%$ xiii

As United Nation (UN) report stated, 'developing countries with large youth populations could take their economies soar, provided they invest heavily in young people's education, health and protect their rights. ${ }^{\text {xiv }}$ 


\section{Dr. Rekha Maitra}

Based on these reports, it can be elaborated that India has an incredible potential to rise as an economic power with a thriving future. A decade-long study by Harvard University's Centre for International Development predicts that (businessworld.in)'the country's GDP will continue to expand at an average of over 7\%, which means nominal GDP will nearly double to around USD 4.50 trillion (at current exchange rate) in 2025. ${ }^{\mathrm{xv}}$

Under the flagship of 'Make in India' the 25 industry sectors i.e automobile, aviation, biotechnology, chemicals, food processing, tourism and hospitality,wellness etc.. have been identified for investment in manufacturing, the government has also launched progressive initiatives like:

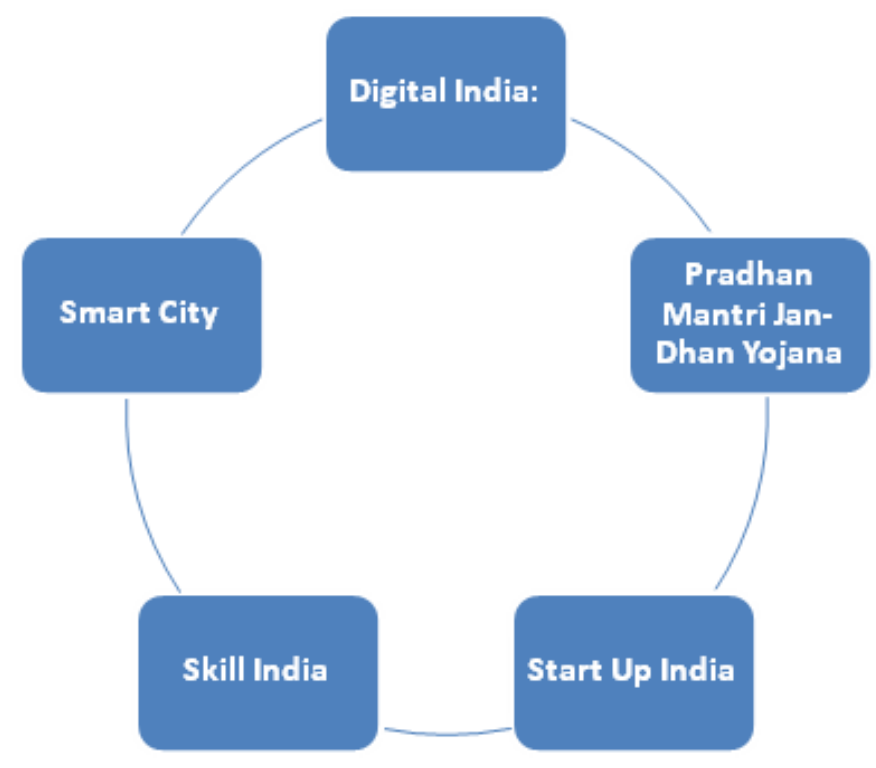

Figure2. Progressive initiatives taken by the Government

- Digital India: This initiative is likely to connect rural areas with high-speed internet networks; boost electronics manufacturing, transforming India into a digitally empowered society and knowledge economy.

- Start Up India: The enterprise aims at fostering entrepreneurship and promoting innovation by creating an ecosystem that is conducive to growth of Startups. An event named Startup Jalsa held in Faridabad attracted a large number of startup entrepreneurs from all over the world.

- Skill India: An initiative will aim at encouraging the development of skill force across India by including the National Skill Development Mission, National Policy for Skill Development and Entrepreneurship 2015, Pradhan Mantri Kaushal Vikas Yojana (PMKVY) scheme and the Skill Loan scheme. Over 400 million people will be trained in various skills by 2022 .

- Pradhan Mantri Jan-Dhan Yojana (PMJDY): This program designs to ensure access to different financial services like availability of basic savings bank account, access to need-based credit, remittance facility, insurance and pension to the classes in society that economicallychallenged.

- Smart City: This is an urban renewal and retrofitting program with a mission to develop 100 cities all over the country making them citizen friendly and sustainable. (makeinindia) ${ }^{\mathrm{xvi}}$

Make in India' validates that the nation is willing to embrace growth by adopting changes on the journey to becoming an economic superpower. In modern era, smart cars, smart phones, smart TV, smart watch, smart hotels and the exercise of converting cities into smart cities will enrich the country with the better prospects of living standards, employability and sustainability.

The cross-boundary tourism make people move from one place o the other.A tourist in search of accommodation can be offered the multiple options of better connectivity because a smart city creates and sustains resources for the well-aware smart tourist who are generally logged into smart apps through various gadgets. With the onslaught of the information age, tourist have become knowledgeable about what to expect from the product line services. 


\section{ASSOCIATED BENEFITS FOR CITZENS OF A SMART CITY}

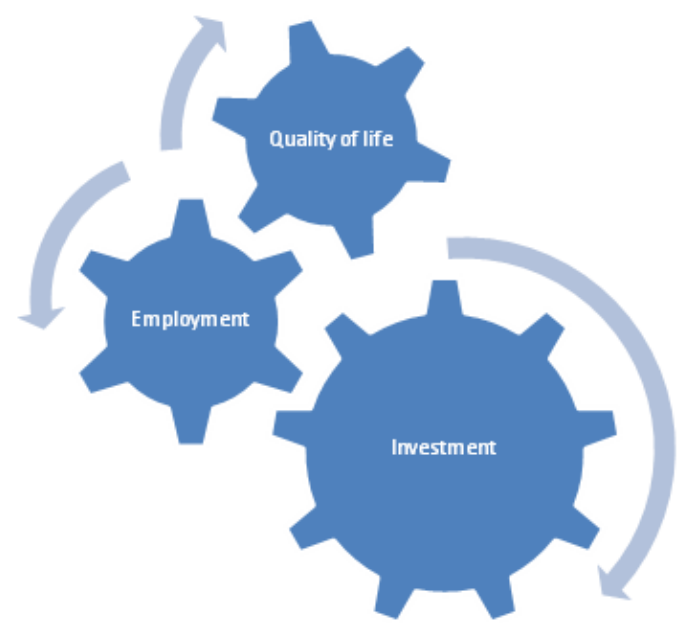

Figure3. Benefits of Smart City

\subsection{Improving Quality of Life for All}

Citizens of smart city can get the quality of life in terms of facilities; economical houses would be widely available equipped with basic facilities,i.e 24 hours electricity back up, diverse range of education services, resources of entertainment, recreation and sports along with security. Faster connectivity will reduce travelling time to nearby locations Reputed schools and hospitals will be effortlessly available and accessible to the citizens and tourists.

\subsection{Investment}

In smart city the investment can be made in accordance with human and innate resources. Mega, Corporate can be provided with facilities and amenities. The e-gateway will reduce the security hassles, and will also help to conduct the business with ease post demonetization in India.

\subsection{Employment}

Government is investing in smart city to facilitate people to explore job opportunities in all sectors. Citizens of smart city may not be required to tour to distant places for their jobs. A better salary structure will enhance the better lifestyle.

\section{SMart Concepts of SMart City}

A city is known to be smart because of its innovative concepts, if the economy will develop it will harness the growth for all with proper education and employment for all.Having urban infrastructure i.e good transportation facilities, energy/utilities with the emphasis on protection of environement and a smart e-governance tendering better services to the citizens with the option of participation in direct democracy These cities also represent the quality of life with better livability,workability and employability.

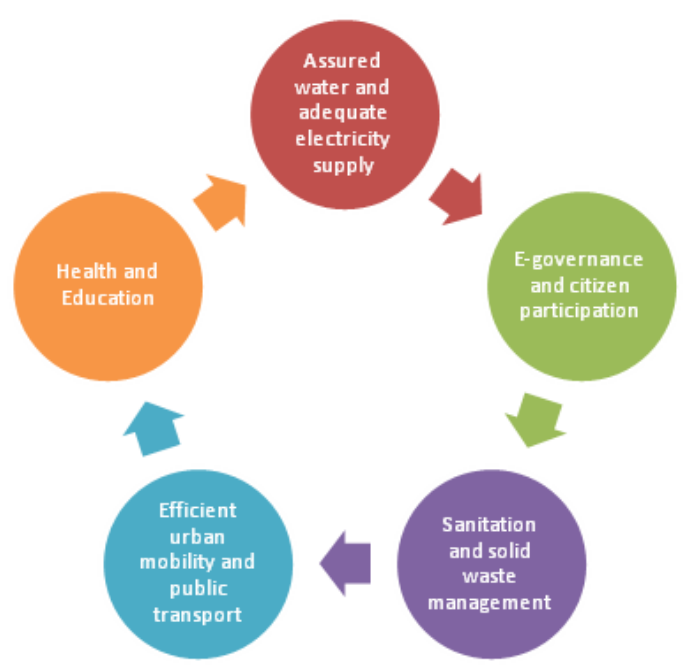

Figure4. Major Requisites of Smart City 


\subsection{Assured Water Supply}

- For having the assured water supply, plantation will help to maintain water sustainability by letting the water seep into the earth. Trees are significant and renewable resource of cooling the earth and air by shading and through water evaporation.

- The citizens must be sensitized to appreciate the significance of green belt for ensuring the quality of drinking water. Excess carbon dioxide (CO2) caused by many factors is a building up in our atmosphere and contributing to climate change. Trees absorb $\mathrm{CO} 2$, removing and storing the carbon while releasing the oxygen back into the air.Trees absorb odors and pollutant gases (nitrogen oxides, ammonia, sulfur dioxide and ozone) and filter particulates out of the air by trapping them on their leaves and bark. As per the National green tribunal (NGT), a city is required to maintain $30 \%$ of the forest/green belt.A well-developed city like Delhi equipped with Metro,International Airport and other significant facilities is left with only $10 \%$ of the afforest area, which is not sufficient to control pollutants in the air.

- Entire city must be provided with water supply.Smart meters should be installed in houses to reduce wastage. The smart metres should be able to gauge faulty leakage for repair to reduce wastage of water.

\subsection{Adequate Electricity Supply}

- The smart citizens, have to learn the way of conserving energy by using energy efficient devices, i.e. CFL and LED lights, LED T.V. Human sensors must be installed at public areas i.e. staircase and washrooms.

- Smart meters should be set up to stop misuse of electricity.

- To reduce the burden on coal, petrol and diesel for daily needs, walking and cycling to nearby places should be promoted and to develop green buildings; solar panels should be installed to conserve energy.

- Misuse of water and electricity must stop and dependency on traditional energy sources must be reduced for long term sustainability.

\subsection{Sanitation and Solid Waste Management:}

- Swatch Bharat campaign in our country emphasizes on clean and hygienic cities in every state. The waste should be recycled for generating fuel and developing manures. Concrete waste should be recycled for reuse and recycled water to be used for farming and other important task.

- Door-to-door collection of garbage should be organized so that people don't need to throw garbage in empty plots; Areas where garbage is usually dumped should be identified and beautified.An initiative of not dumping and burning the garbage in open forum by Government will harness the change to the system.

\subsection{Efficient Urban Mobility and Public Transport}

- Smart parking and intelligent traffic management should be in place with integrated multi-model transport. An intelligent traffic management system with information about traffic jams and advance information of red light signals for smooth driving should be available.

- The ITMS is a hi-tech system which monitors traffic along expressways and guides commuters to adapt speed to ensure a smoother flow of traffic. It will also help to coordinate policing and emergency services. The ITMS is being rolled out by an Austrian company at a cost of nearly Rs 30 crore, and is expected to bring down the accident rate on the high-speed road by nearly $25 \%$. The Noida Authority is gearing up to launch the Intelligent Traffic Management System (ITMS) on the Noida-Greater Noida expressway from January 11 and the trials have begun.

- The development of smart parking and smart phone can give indications for free/vacant parking space.

- Separate lane should be developed for pedestrians and cyclist.

- Metro, buses and autos to be connected via one smart card for smart payment.

- Citizens can no longer be trapped in traffic for hours, which can further increase the mileage of the vehicle and will also help to save fuel. 


\subsection{Education and Health}

- Education sector to be set up for job creation and development of centers for skilled and semi skilled courses. Hunar se Rozgar, Pradhan Mantri Kaushal Vikas Yojana (PMKVY) scheme and the Skill Loan scheme etc. are likely to escalate various job opportunities.

- Launching E-classes can strengthen the distance education system.

- The subject specialist can explain the subjects to students through MOOC video conferencing, graphics and animation for better understanding.

- Medicine, treatment and therapeutic consultancy should be available online.

- E-medical consultancy services to be introduced and awareness should be spread through various advertisements on the Internet.

- Diseases related to pollution can reduce by enhancing the green belt

- Doctor's across the globe should be accessible through online mode for consultancy.

\subsection{E-Governance and Citizen Participation}

- Public information \& Grievance Redressal system like F.I.R should be online, where in the citizen can track their case. Government schemes, rules and regulations can be available online.

- Involvement of ordinary citizens in the development and organizations of government projects as they are the city's eyes and ears. ,

- CCTV camera's to be installed, inspected, recorded and regulated for all services.

- Electricity bill and other bills to be released with the option of online payment.

- A smart city can enhance our quality of life and investment can be made to develop infrastructure and employment.

- Online complaints handling can decrease the unnecessary visits to offices.

\section{Obstacles In THE WaY TO SMart City}

A poor country like India has more threats and critical issues before dealing with the concept of a smart city. The poverty coupled with illiteracy is an arduous challenge to deal with. The rate of literacy in India is $74.04 \%$. "India, along with the Arab states and sub-Saharan Africa, has a literacy level below the threshold level of $75 \%$, but efforts are on to achieve that level. The campaign to achieve at least the threshold literacy level represents the largest ever civil and military mobilization in the country" "xvii If the literacy rate increases b then there would be more sensible in dealing with the current problems,. We need to get together and work out a strategy to achieve the mission .

\section{The safest places to travel in the world}

Index rankings of the 15 most peaceful countries worldwide in 2015

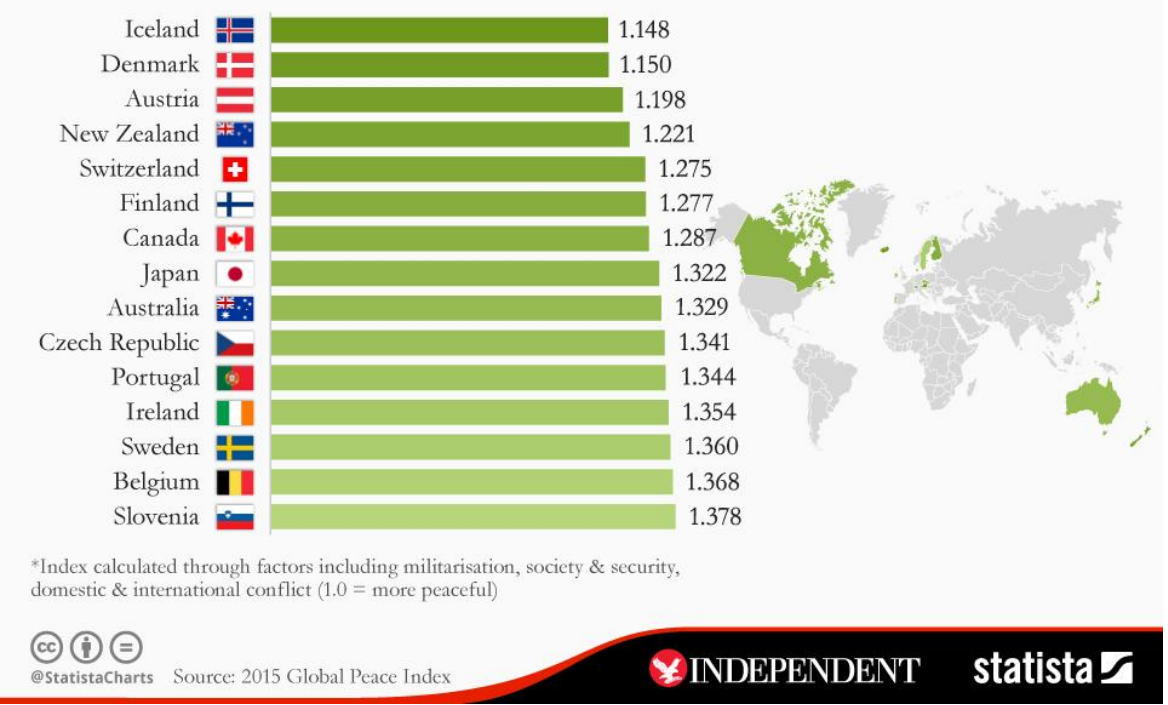

Figure5. Global Travel and Tourism Industry Infographic - The safest places to travel in the world (Reference: Statista.com) ${ }^{\text {viii }}$ 


\section{Dr. Rekha Maitra}

The above figure represents the global travel and tourism industry infographic, which explains that India is not considered to be the safe destination for the tourist and this is one of the major threat as it destroys the brand image of Incredible India. The tourism ministry in the Union budget has received an allocation of Rs 1,590 crore, to focus on infrastructure development and promotion and publicity initiatives" (TOI, 2016), but regardless of all these India is listed under the unsafe destination.

Smart city or Swatch city seems to be a distant dream. The local vendors on the roadside, contribute their own share of garbage. Condition of roads is horrible; everywhere, garbage \& waste construction material is scattered;Cows roam freely and their dung is found everywhere in today's Swatch Bharat.

Smart City with target population of 5 to 10 lakhs in every city is likely to require financial investment ranging between INR 75,000 and 150,000 crores and may require $8-10$ years for implementation.

Any action must be collective to be effective and we must contribute significantly to be part of development.In this regard, Municipal corporation of different cities have organized various smart city competitions i.e. poster making,national contest etc. by involving the citizens for showcasing their talent and ideas through participation. https://www.mygov.in/ is an active partner in nationbuilding where one can participate in groups, tasks, discussions, polls, blogs and talks etc. by being a contributor to the development.

"The big challenge will be to create self-sustaining cities, which create jobs, use resources wisely and also train people. The idea should be to make cities work for the masses. India has to now take an important decision in the context of creating smart cities. It has to determine if it desires to opt for making new cities or upgrade existing ones". (Kandpal, 2016)

The emergence of blogs and e-communities have brought the revolution of change, wherein people come together to discuss the city related issues.Together they come out with solutions and take the pledge to solve it.Local circles is an e-community, where people speak one language for the development of India as a country.Almost 95 lac people are associated with it through different national circles.

We can talk about making a difference, or we can make a difference.

\section{Conclusion}

India is not safe and clean, it lacks in basic infrastructure and significant facilities,i.e transport is the thought process of domestic and international tourists.Till date,India is regarded as Third world country and such countries are stereotyped to be referred as poor and non-industrialized country. Safety and security of citizens and foreign nationals are the two critical issues in India. One bad incidence is enough to tarnish the brand image of Incredible India.The country has to be safe for its people with the aim of making it safe for all the travelers. We have to condemn our own weakness in order to gain strength.The special focus on these factors will help us to envisage India as a nation of smart cities.

In order to improve the international image like other countries, these smart cities can possess all needed necessities like city safety, transport connections, street lighting and police patrolling to ensure safe tourism. These smart cities can be connected with metro cities for the ease of foreign travelers to easily commute from airports to hotels and visiting tourist destinations in the smart cities. This can lead to better arrangements of food and accommodation facilities they prefer. Tourism can provide an overall development of the hospitality sector. There can be numerous opportunities for the skilled professionals in the tourism and hotel industry.

To develop smart cities in India,we need to address challenges of illiteracy, political issues, financial management etc. We must not forget India is a democratic country and democracy is of the people by the people and for the people therefore involvement of citizens will help to make the cities smart cities. The government needs to set the priority of making our country neat and clean to improve its image.Swach Bharat cannot be a one man army,this army has to be led by one and all.

"We can change the world and make it a better place.It is in our hands to make a difference". Nelson Mandela 


\section{REFERENCES}

(W3C/CTIC), J. M. (2009, May 12). Improving Access to Government through Better Use of the Web. Retrieved January 2017, 15, from http://www.w3.org/TR/2009/NOTE-egov-improving: http:// www.w3.org/TR/2009/NOTE-egov-improving-20090512/

Das, D. (May 2015). What is a Smart city? New Delhi: The Times of India.

Dutt, S. (2015, April). Smart Cities, Smart Investors. Business Today, p. 81.

Ebi, K. (2014, July 18). http:/izi.travel/en/blog/. Retrieved November 18, 2016, from Smarter tourism: What are these cities doing right?: http:/izi.travel/en/blog/smart-city-the -power of networking

Financial Express, Smart City full list. (2015, September Wednesday). Retrieved December 20, 2016, from www.financialexpress.com: http://www.financialexpress.com/article/economy/smart-citieslist-check-which-cities-have-been-selected-in-pm-modis-smart-city-mission/126368/

ibpsguide.in. (2016). Monthly Current affais capsule. New Delhi: http://www.ibpsguide.in/PDF/ Monthly_Current_Affairs_Capsule-April_2016-www.ibpsguide.com\%20(1).PDF.

Journaldunet. (n.d.). Retrieved January 2017, 15, from http://www.journaldunet.com.

Kakodkar, P. (2016). 11.8\% growth in foreign tourist arrivals in August 2016. New Delhi: The Times of India.

Kandpal, V. (2016, April 7). Challenges In Financing Smart City Projects In India. Retrieved Nove,mber 18, 2016, from http:// swarajyamag.com/: http://swarajyamag.Com/smart-cities/challenges-in-financing-smart-city-projects-in-india

Kumar, P. (July 1, 2015). What is the real mean of smart city? Delhi: Smart cities News, Smart city Projects.

makeinindia. (n.d.). make in India. Retrieved December 15, 2016, from http://www.makeinindia.com: http://www.makeinindia.com/article/-/v/digital-india-transforming-india-into-a-knowledgeeconomy

Murty, A. L. Challenges before Construction Industry in India. Department of Civil Engineering,IIT Kanpur http://www.iitk.ac.in/nicee/RP/2004_Challenges_Construction_Industry_Proceedings.pdf.

Musa, D. (2016, Jan). Smart City Roadmap. Retrieved 23 December, 2016, from http://www.Academi a.edu/ : http://www.academia.edu/21181336/Smart_City_Roadmap

Mygov.in. (2015, September 15). List of projects. Retrieved 11 january, 2017, from http:// smartcities. gov.in: http://smartcities.gov.in/writereaddata/List_of_Projects_60_Cities.pdf

mygov.in. (2015, November). Smart Cities Challenge - MCGM. Retrieved January 15, 2017, from https://www.mygov.in: https://www.mygov.in/sites/default/files/mygov_1443508845190667.pdf

NL, A. (2016). smart cities in India. Retrieved from http://www.agentschapnl.nl.

Rvo. (2015). Smart Cities in India. Retrieved from www.rvo.nl/sites/smart/cities/india: http://www. rvo.nl/ sites/default/files/Smart\%20Cities\%20India.pdf

Sharma, P. (2016, Dec 7). Smart city Projects:Germany Supports for High-Speed Railway in India's Smart Cities. Retrieved Dec 25, 2016, from smartcityproject.com

Timetric. (2014). Travel and Tourism in India to 2018. New Delhi: http://marketreportsstore.com /toc/?rname $=15258$.

tmb. (n.d.). Retrieved January 2017, 15, from https://www.tmb.cat/: https://www.tmb.cat/ca/home

tmb. (n.d.). Retrieved 15 January, 2017, from https://www.tmb.cat/ca/: https://www.tmb.cat/ca/home

TOI. (2016). Budget 2016: Tourism gets 70\% hike. New delhi: The Times of India.

Wakefield, C. \&. (2015). Modern Urbanization Challenges in setting up Smart Cities.india.Smart cities council.com/system/tdf/.../SmartCitiesReportCW.pdf?file...type...

Worstall, T. (2016, May 31). India's Economic Growth Up To 7.9\% Of GDP For Quarter, 7.6\% For The Year. Retrieved January 15, 2017, from http://www.forbes.com/: http://www.forbes.com/ sites/ timworstall/2016/05/31/indias-economic-growth-up-to-7-9-of-gdp-for-quarter-7-6-for-theyear/\#6ad417e94777 
Yadav, A. (2015, May). Tourism Prospects in the Modi Era. Hotel \& Restaurants Network , pp. 3840.

yoursingapore. (n.d.). Retrieved January 15, 2017, from http://www.yoursingapore.com: http://www .yoursingapore.com/ en.html

\footnotetext{
${ }^{i}$ India's Economic Growth Up To 7.9\% Of GDP For Quarter, 7.6\% For The Year

${ }^{\text {ii }}$ UNWTO http://statistics.unwto.org/content/data-1

iii Indian smart cities mission https://www.bloomberg.org/program/government-innovation/india-smart-citiesmission/

${ }^{\text {iv }}$ Dr. Sam Musa http://www.academia.edu/21181336/Smart_City_Roadmap

${ }^{v}$ New Delhi Smart City Project will implement by June 2018 November 3, 2016 Pradeep Kumar Smart Cities News, Smart City Projects

${ }^{v i}$ http://newsroom.mastercard.com/wpcontent/uploads/2014/07/Mastercard_GDCI_2014_Letter_Final_70814.P df

${ }^{\text {vii }} \mathrm{http}: / / \mathrm{www}$.yoursingapore.com/en.html

viii $h$ ttps://www.tmb.cat/ca/home

${ }^{\text {ix }}$ http://www.journaldunet.com/economie/services/1174028-smart-tourism-destination/

${ }^{x}$ Smart city Projects Posted: 07 Dec 2016 01:13 AM PST Germany Supports for High-Speed Railway in India's Smart Cities

${ }^{x i}$ November 22, 2016 Pradeep Kumar Smart Cities News, Smart City Projects

xii $\mathrm{http} / / /$ www.ibtimes.co.uk/india-surpasses-china-become-fastest-growing-economy-world-1542725

xiii http://articles.economictimes.indiatimes.com/2016-05-04/news/72832025_1_gdp-growth-growth-forecastregional-economic-outlook

${ }^{\text {xiv } h t t p: / / w w w . t h e h i n d u b u s i n e s s l i n e . c o m / n e w s / i n d i a-h a s-w o r l d s-l a r g e s t-y o u t h-p o p u l a t i o n-u n-~}$ report/article6611138.ece

${ }^{\mathrm{xv}} \mathrm{http}: / /$ businessworld.in/article/Harvard-Study-Places-India-On-Top/26-01-2016-90622/

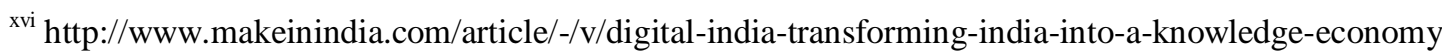

xvii National Literacy Mission website". Nlm.nic.in. Retrieved 2010-09-01.

xviii ttps://www.statista.com/topics/962/global-tourism/
} 